\title{
¿QUÉ SIGNIFICA JUZGAR? *
}

\author{
Antonio-Enrique Pérez Luño \\ Universidad de Sevilla
}

RESUMEN. Este trabajo tiene por objeto el análisis del significado del juicio; para ello se realiza una triple aproximación. En primer término, se estudia la dimensión creativa de la tarea judicial, y su relevancia como fuente del Derecho. Se elabora a este fin, un mapa doctrinal sobre las distintas tesis relativas al valor creativo de la jurisprudencia. Se estudia, en segundo término, la definición ostensiva del juicio, a partir de su localización externa en distintos ámbitos o establecimientos espaciales. La última y más extensa parte del trabajo, se propone indagar los elementos constitutivos del proceso judicial. Se estudian aquí, sucesivamente, los aspectos perceptivos, racionales y decisionales que conjuntamente conforman la tarea de juzgar. En este apartado se analizan, con especial atención, las controversias doctrinales que enfrentan la concepción lógico-formal y la concepción argumentativa del razonamiento del juez. El ensayo se concluye con unas observaciones de síntesis sobre la convergencia entre las dimensiones básicas del Derecho y los tres aspectos constitutivos de la acción de juzgar Se postula la necesidad de una visión integradora de esos aspectos, al considerarse que las teorías fragmentarias y unilaterales sobre la labor del juez, han contribuido a oscurecer y confundir su significado

Palabras clave: juicio, jurisprudencia, fuentes del Derecho, arbitrio judicial, razonamiento judicial, argumentación judicial, motivación de las decisiones judiciales.

ABSTRACT. The aim of this paper is to analyze the meaning of the legal process. Three steps are followed. First, both the creative dimension of judicial tasks and their relevance as a legal source are studied. With that aim, a theoretical map describing different theses on the creative value found in case-law is elaborated. Secondly, the ostensive definition of the legal process is studied, taking its external localization in varied placements and environments as a starting point. The last and longest part of the paper aims at elucidating the constitutive elements in a legal process. Perceptive, rational and decisional elements - all of them core parts of the judging task - are here widely studied. The opposed visions that regard judicial reasoning as either formal-logical or argumentative are carefully analyzed. The essay concludes with some summary observations on the converging between the basic legal dimensions and the three constitutive aspects of the judging activity. An integrated vision of the aforementioned aspects is postulated, considering that fragmentary and unilateral theories have much contributed to misunderstand the meaning of judicial activity. tion.

Keywords: legal process, case-law, legal sources, legal reasoning, legal argumenta-

* Fecha de recepción: 28 de marzo de 2009. Fecha de aceptación: 27 de abril de 2009. 


\section{PLANTEAMIENTO: SOBRE LA EQUIVALENCIA ENTRE LOS TÉRMINOS «JUICIO»Y «DERECHO»}

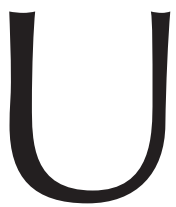

no de los más notorios libros de M. HeIDEGGER expresa en su título una interrogación radical: Was heisst Denken? (¿Qué significa pensar?). Porque, en efecto, la tarea principal e ineludible del filósofo consiste en clarificar el significado de su propio quehacer; es decir, de lo que representa el ejercicio del pensamiento ${ }^{1}$.

De modo análogo, existe una cuestión básica e insoslayable para el jurista que se concreta en la necesidad de ofrecer cumplida respuesta al interrogante: ¿qué significa juzgar? La exigencia de plantear y responder a esa pregunta dimana de la equivalencia, sustentada en el pasado y en el presente, entre los términos de: «juicio» y «Derecho».

El romanista A. D'Ors afirma que en el Derecho romano se daba una continuidad entre las palabras ius, es decir, el Derecho y iudicium, que es el juicio. El «juicio» (ius-dicere) significa «declaración» de lo que es ius. De ello, infiere D'Ors, que: «la conexión ius-iudicium nos lleva a la definición de lo que es el ius, esto es el Derecho... Allí donde hay un juicio, sea popular, sea por jueces libres o burocráticamente organizados, hay una declaración de ius. Lo que en tal juicio se declare justo, eso es Derecho, el Derecho». Para A. D'Ors, esa equivalencia se ha mantenido a través de la historia y sigue siendo vigente, por lo que no duda en concluir que al seguir siendo en la actualidad los jueces los que hacen las declaraciones de lo que es Derecho, «podremos definir el Derecho como aquello que declaran los jueces (ius, quod iudex dicit)»².

En la cultura jurídica contemporánea se ha hecho notoria la postura del realismo norteamericano tendente a identificar la entera significación del Derecho con el quehacer de los jueces. No huelga recordar, al respecto, la concluyente tesis de R. GRAY de que: «all the Law is judge-made Law» ${ }^{3}$, para captar el peso decisivo que corresponde a la judicatura en el ordenamiento jurídico. Asimismo, se debe al célebre juez de la Corte Suprema norteamericana O. W. HolmEs la penetrante observación de que el estudio del Derecho no supone el descubrimiento de algo misterioso, sino de una realidad bien conocida, es decir, de la actuación de los jueces ${ }^{4}$. Desde esas premisas, el análisis del comportamiento judicial aparece como la condición necesaria para trasladar desde la penumbra y el misterio a la transparencia y la claridad el significado del sistema jurídico en su conjunto.

\section{EL JUICIO COMO FUENTE JURÍDICA: ¿LOS JUECES CREAN DERECHO?}

La identificación del concepto general del Derecho con las decisiones judiciales se enfrenta a un importante escollo jurídico y político. Se trata de la exigencia pos-

1 M. HeIDEgGer, Was heisst Denken?, Tübingen, Max Niemeyer, 1954.

2 A. D’Ors, Una introducción al estudio del Derecho, Madrid, Rialp, 1963, pp. 108-110.

3 R. GRAY, The Nature and Sources of the Law, se cita por la reimp. sobre la 2. ${ }^{a}$ ed., 1921, de P. SMITH, Gloucester, Mass., 1972, p. 125.

4 W. Holmes, The Path of the Law en Collected Legal Papers, New York, Harcourt, 1920, p. 167. 
tulada por el racionalismo jurídico, que será germen del movimiento constitucionalista formulador del Estado de Derecho, de establecer el principio de la división de poderes.

A tenor de ese principio, que halló nítida expresión en la doctrina de MONTESQUIEU, se reserva a la ley, en cuanto norma general y abstracta promulgada por el Parlamento, la definición de los aspectos básicos del status jurídico de los ciudadanos. Por eso, se ha hecho célebre la máxima del propio MONTESQUIEU de que los jueces deben atenerse al texto estricto de la ley y que los jueces son «la boca que pronuncia las palabras de la ley, seres inanimados que no pueden moderar ni la fuerza ni el rigor de ellas» ${ }^{5}$.

Esta visión del juez como autómata que se limita a aplicar las consecuencias jurídicas previstas en las normas legales a los hechos que se enjuician en el proceso, obtuvo su elaboración doctrinal definitiva en la teoría de la subsunción elaborada por la dogmática jurídica positivista. Según postula esta teoría, la función judicial se circunscribe a encajar los hechos controvertidos en los supuestos fácticos tipificados en las leyes y aplicarles las consecuencias jurídicas en ellas previstas, de acuerdo con el consabido apotegma: «da mibi facti, dabo tibi ius». De ello se infiere que, desde estas premisas, se concibe la tarea del juez como la mera declaración de un derecho preexistente (el sistema normativo legal) y no como un dato constitutivo de la definición del Derecho.

Esta imagen de la jurisprudencia ha calado profundamente en la cultura europea. Es probable que una de las expresiones más radicales de su sentido y consecuencias se deba a J. ORTEGA y GASSET, quien en una reflexión merecedora de ser rescatada del olvido por parte de las tentativas de analizar las proyecciones jurídicas del raciovitalismo, expone cuanto sigue: «El que juzga no entiende. Para ser juez es preciso hacer previamente la heroica renuncia a entender el caso que se presenta a juicio en la inagotable realidad de su contenido humano. La justicia mecaniza, falsifica el juicio para hacer posible la sentencia. No es, pues, extraño que del inmenso volumen de la historia universal se puedan espumar tan pocos nombres de jueces inteligentes. Aunque personalmente lo fueran, su oficio les obligó a amputar su propia perspicacia. Este es el triste heroísmo del juez, sin el cual la convivencia humana no resultaría posible. Vaya nuestro respeto a esa dolorosa profesión; pero de paso detestemos a los que sin ejercerla se constituyen tan fácil y alegremente en jueces de afición» ${ }^{6}$.

Es evidente que esta concepción mecanicista de la tarea judicial entraña una simplificación y falsea el alcance del proceso y su relevancia en la conformación de la experiencia jurídica. Los últimos años han supuesto un alejamiento de la tesis subsuncionista, incluso desde enfoques positivistas o, más bien, desde el denominado «postpositivismo jurídico». En cualquier caso, la pugna entre la concepción pretoriana o judicialista del Derecho y la concepción legalista del mismo ha sido uno de los grandes nudos temáticos de la metodología y la ciencia jurídicas contemporáneas. La relevancia de la función judicial como fuente del Derecho y sus repercusiones para la garantía

5 Montesquieu, Esprit des lois, XI, 5.

6 J. ORTEGA y GASSET, «Prólogo a una edición de sus obras», en Obras completas, vol. 6, Madrid, Alianza Editorial y Revista de Occidente, 1983, p. 343. 
de la seguridad jurídica, constituye un capítulo insoslayable de las trayectorias más recientes de la cultura jurídica ${ }^{7}$.

Un estimulante y provechoso intento dirigido a clarificar los términos de esa polémica se debe a G. R. CARRIÓ en su lúcido ensayo: «Los jueces crean Derecho». En opinión de Carrió la actitud que se asuma respecto a ese postulado engendra dos posturas irreconciliables: «los que afirman enfáticamente que es verdadero, y los que, con igual énfasis, sostienen que es falso. Para los primeros, la posición de los segundos importa negar una característica obvia de la práctica del Derecho... Para los segundos, la posición de los primeros importa desconocer una distinción tan elemental como la que existe entre las nociones de creación y aplicación de normas jurídicas, negar la evidente fuerza obligatoria del Derecho y, por lo tanto, fomentar la anarquía y el caos» ${ }^{8}$.

De este trabajo se infiere la exigencia de precisar y distinguir los conceptos que integran esa expresión. Porque para entender lo que la misma significa es preciso plantear previamente: ¿qué derecho? ¿qué jueces? y ¿qué creación? constituyen el objeto de nuestros asertos. Es evidente que de la multívoca pluralidad de concepciones del Derecho se derivan diferentes respuestas a esa cuestión. De igual modo, la imagen del juez depende de las múltiples concepciones jurídicas, así como de los distintos sistemas del Derecho comparado, siendo notorias las diferencias al respecto que se derivan de los sistemas romanistas, del Common Law, de los sistemas escandinavos, socialistas...

En relación con el significado que el término «crear» asume en la expresión de referencia, estimo que pueden distinguirse analíticamente hasta ocho actitudes teóricojurídicas. Éstas, clasificadas desde la versión más fuerte a la más débil de la idea de creación, responden a las tesis siguientes:

1. ${ }^{\text {a) }}$ Crear/juzgar como demiurgia. Si se asume el término «demiurgo» en la acepción platónica de fuerza creadora y suprema, pueden englobarse aquí las tesis reseñadas supra de autores como D'ORs, GRAY o HOLMES, para quienes no sólo los jueces crean Derecho, sino que de ellos procede todo el Derecho, es decir, que sólo los jueces son fuente del Derecho.

2. $\left.{ }^{a}\right)$ Crear/juzgar como manifestación del arbitrio judicial. En distintos momentos del desarrollo histórico del Derecho y para algunos movimientos de la cultura jurídica contemporánea, entre los que pueden incluirse la Escuela del Derecho libre y las versiones más radicales del denominado «uso alternativo del Derecho», el juez se halla investido de la potestad de establecer normas jurídicas. Esa facultad puede ejercitarla cuando las exigencias del caso controvertido lo hace necesario, atendiendo a su punto de vista sobre la justicia, a su idea del bien o a su sentido común ${ }^{9}$.

3. $\left.{ }^{a}\right) \quad$ Crear/juzgar como capacidad para producir normas ex ius naturae o ex natura rei. Esta tesis coincide con la anterior en postular la legitimidad del juez para

7 Cfr. A. E. PÉrez LuÑo: La seguridad jurídica, 2. ${ }^{a}$ ed., Barcelona, Ariel, 1994, pp. 133 y ss.; El desbordamiento de las fuentes del Derecho, Sevilla, Real Academia Sevillana de Legislación y Jurisprudencia, 1993, pp. 13 y ss.; Trayectorias contemporáneas de la Filosofía y la Teoría del Derecho, 5. ${ }^{a}$ ed., Madrid, Tébar, 2007, pp. 23 y ss.

8 G. R. CARRIÓ, «Los jueces crean Derecho», en su vol., Notas sobre Derecho y lenguaje, 6. ${ }^{a}$ reimpresión, Buenos Aires, Abeledo-Perrot, 1976, pp. 79-80.

9 Cfr. J. AnsuÁtegui, «Creación judicial del Derecho: crítica de un paradigma», en la obra El Derecho en Red. Estudios en Homenaje al profesor Mario G. Losano, Madrid, Dykinson, 2006, pp. 519 y ss. 
crear normas jurídicas por exigencias de justicia, pero difiere de ella en que le impone el deber de inspirar y orientar su decisión en un parámetro normativo objetivo: el Derecho natural o su modalidad de la «naturaleza de las cosas». La célebre teoría de G. RADBRUCH, según la cual el juez debe oponer a la legalidad inicua el Derecho supra legal, constituyen un ejemplo diáfano de esta postura. El propio RADBRUCH en su monografía Die Natur der Sache als juristische Denkform (La naturaleza de la cosa como forma de pensamiento jurídico) ${ }^{10}$, estimuló una corriente doctrinal que concebía la «naturaleza de las cosas» como fuente jurídica inspiradora de las potestades creativas de la jurisprudencia ${ }^{11}$.

4. a) Crear/juzgar como capacidad de integración normativa. En las últimas décadas del pasado siglo, se puede considerar como una postura representativa de este planteamiento a la de R. DWORKIN. DWORKIN tiende a evidenciar el carácter fragmentario e insatisfactorio de las tesis que hacen reposar la validez del sistema de fuentes en criterios formales normativos. A partir de ello, se haría depender la validez de las normas concretas de su conformidad con las normas de procedimiento que en cada ordenamiento jurídico regulan la producción jurídica (teoría que es calificada por DWORKIN como test del pedigree). No menos rechazable le parecen las doctrinas que reconducen la validez al dato puramente fáctico de la eficacia de las normas, es decir, al hecho de su aplicación y cumplimiento mediante una determinada práctica social. El rechazo de cada una de estas posturas le conduce también al rechazo del sincretismo de ambas, tal como se desprendería de las tesis de HART. En la teoría del Derecho como integridad, que sostine DWORKIN, ocupan un lugar privilegiado los principios. Según la notoria tesis de DwORKIN, todo ordenamiento jurídico se halla integrado por un conjunto de principios (principles), medidas o programas políticos (policies) y reglas o disposiciones específicas (rules). DWORKIN denomina medidas políticas a las normas genéricas (standards) que establecen fines que deben alcanzarse y que implican un avance en el terreno económico, político o social para la comunidad; mientras que reserva la denominación de principios a los standards o prescripciones genéricas que entrañan un imperativo de justicia, de imparcialidad, o de cualquier otra dimensión de la moralidad. Son los principios, en cuanto entrañan los fundamentos morales del orden jurídico y la expresión de los derechos básicos de los ciudadanos, los que aseguran la coherencia y plenitud del sistema de normas que hace posible el imperio del Derecho y que, por tanto, deben ser la pauta orientadora de la labor judicial ${ }^{12}$.

5.) Crear/juzgar como capacidad para completar el proceso normativo. Se ha producido durante las últimas décadas, una metamorfosis en el concepto de norma

${ }_{10}$ G. RADBRUCH, «Leyes que no son Derecho y Derecho por encima de las leyes», en el vol. Derecho injusto y Derecho nulo, trad. cast. de J. M. RodrígueZ Paniagua, Madrid, Aguilar, 1971; id., La naturaleza de las cosas como forma del pensamiento jurídico, trad. cast., de E. GARZÓN VALDÉs, Córdoba (Argentina), Universidad de Córdoba, 1963.

${ }_{11}$ Cfr. E. GARZÓN VALdÉs, Derecho y «naturaleza de las cosas». Análisis de una nueva versión del Derecho natural en el pensamiento jurídico alemán contemporáneo, Córdoba (Argentina), Universidad de Córdoba, 1970.

12 R. Dworkin, Taking Rights Seriously, 2. ${ }^{a}$ ed., London, Duckworth, 1978 (existe trad. cast. de M. GuASTAvino, con Prólogo de A. Calsamiglia, Barcelona, Ariel, 1984); id., A Matter of Principle, Cambridge (Mass.), Harvard University Press, Cambridge (Mass.) and London, 1985; id., Law's Empire, Fontana, London, 1986, (Existe trad. cast. de C. FERRARI, revisada por E. ABRIL, Barcelona, Gedisa, 1988); id., Sovereign Virtue. The Theory and Practice of Ecuality, Cambridge (Mass.) and London, Harvard University Press, 2000. id., Justice in Robes, Cambridge (Mass.) y London, Harvard University Press, 2006, (existe trad. cast., de M. IgLESIAS e I. OrtiZ DE UrbinA, Madrid, Marcial Pons, 2007). 
que tiene consecuencias inmediatas en la forma de concebir la función judicial. Hoy se tiende a sustituir la noción de norma jurídica como «norma dato», es decir, las formulaciones promulgadas por el legislador, por la de «norma resultado», que supone el momento completo y culminante de la elaboración normativa por los operadores jurídicos, en especial, por los tribunales. De ello, se desprende que para las corrientes jurídico-metodológicas actuales la norma no es el presupuesto, sino el resultado de un proceso de elaboración e interpretación en el que a la judicatura le corresponde un protagonismo incuestionable ${ }^{13}$.

6. ${ }^{a}$ Crear/juzgar como capacidad excepcional para producir normas. Esta tesis corresponde a quienes circunscriben la facultad creadora de la judicatura a las situaciones excepcionales en las que el juez puede formular normas generales, como en los supuestos de lagunas ${ }^{14}$.

7. ${ }^{\text {a) }}$ Crear/juzgar como facultad para elegir el significado normativo. Esta tesis podría hallarse representada por la difundida concepción normativa de Herbert HART, según la cual la actividad judicial se lleva a cabo a través de un proceso necesario de atribución de un sentido a las normas. Ya que, según HART, toda norma posee una estructura abierta (open texture), susceptible de asumir diversos significados posibles. Entre ellos, el juez elige el que estima más adecuado a las circunstancias y esa elección implica un reconocimiento de su libertad de opción ${ }^{15}$.

8. $\left.{ }^{a}\right)$ Crear/juzgar como posibilidad de producir normas individuales. Según se desprende de la Teoría pura del Derecho de H. KELSEN, el ordenamiento jurídico se halla conformado por normas generales y abstractas, creadas por el poder legislativo y los órganos administrativos competentes para ello, y normas individuales y concretas representadas por las sentencias judiciales. Los jueces al proyectar los supuestos genéricos y abstractos previstos en las normas generales a los casos concretos, llevarían a cabo un proceso de individualización que supondría la facultad creadora de normas individuales ${ }^{16}$.

Conviene reparar en que de las tesis reseñadas, sólo la 1. ${ }^{a}$ reivindica el monopolio judicial de la creación del Derecho. En las restantes, no se pone en cuestión la compatibilidad de las funciones creadoras del juez con la existencia de otras fuentes de producción de normas jurídicas. Las tesis $2 .^{a}, 3$. $^{\mathrm{a}}$ y 4 . $^{\mathrm{a}}$ suponen la versión «fuerte» de la expresión: «los jueces crean Derecho»; mientras que las tesis 5. y $6 .^{a}$ representan la versión «débil» de la misma. La tesis 5 . $^{a}$ sostiene que el proceso de creación de normas jurídicas exige la necesaria concurrencia de una pluralidad de actores, siendo la judi-

${ }_{13} C f r$ r. sobre estas tendendias jurídico-metodológicas actuales, A. E. PÉREZ LuÑo, El desbordamiento de las fuentes del Derecho, cit., pp. 48 y ss.; id., Derechos humanos, Estado de Derecho y Constitución, 9." ed., Madrid, Tecnos, 2005, pp. 260 y ss.

${ }^{14}$ En fecha reciente ha defendido esta tesis, que es compartida por distintas concepciones jurídicas postpositivistas, E. BULYGIN, «Los jueces ¿crean Derecho?» en el vol. col., La función judicial, a cargo de J. MALEM, J. OROZCo y R. VÁzQuez, Barcelona, Gedisa, 2003, pp. 21 y ss. En esta obra se desliza una errata ciertamente paradójica. La obra de H. KelSEN, Reine Rechtslehre (Teoría pura del Derecho), aparece citada por uno de esos duendes tipográficos o procesadores de textos «inteligentes», como: Teoría fuera del Derecho, en la p. 37 , nota 16. De este modo, la doctrina de KELSEN que constituye el intento más depurado de elaborar una teoría interna, es decir, «desde dentro» del Derecho, aparece convertida en una doctrina «fuera» del Derecho.

${ }^{15}$ H. HART, The Concept of Law, Oxford, Clarendon Press, 1961, pp. 120 y ss. (existe trad. cast. de G. R. CARrió, Buenos Aires, Abeledo-Perrot, 1963 y México, Nacional, 1980).

${ }^{16}$ H. Kelsen, Reine Rechtslehre, 2. ${ }^{a}$, Wien, Franz Deuticke, 1960, pp. 242 y ss. (existe trad. cast. de R. VERNENGO, México, UNAM, 1979). 
catura uno de ellos. La tesis $6 .{ }^{a}$ limita la creación judicial a supuestos excepcionales que confirman la regla general de que la producción de normas es competencia del legislador; y que a la judicatura le incumbe su aplicación. Las tesis $7 .^{a}$ y $8 .^{a}$, pese a lo que pudiera sugerir su enunciado, constituyen respuestas negativas a la posibilidad de atribuir a los jueces la función creadora del Derecho. La concepción de HART no implica el reconocimiento de un poder creador en manos del juez, sino una concepción flexible y abierta del proceso hermenéutico a través del cual el juez aplica las normas. Asimismo, la postura de KELSEN no debe llevar a engaño, porque, en su significado estricto y consecuencias, no entraña algo opuesto a la teoría de la subsunción defendida por el positivismo jurídico legalista. Conviene advertir, al respecto, que para KELSEN, el ordenamiento jurídico es una estructura piramidal estrictamente jerarquizada, en la que toda norma apoya su validez en la superior. En función de esa estructura escalonada (Stufenbau) del orden jurídico postulada por H. KELSEN, la pretendida «creatividad» del juez para formular normas individuales, se circunscribe a individualizar las consecuencias previstas en las normas generales, es decir, a aplicar lo previsto en las normas generales a los casos controvertidos.

Debe señalarse también que las acepciones del término «crear» se hallan inmediatamente vinculadas a las distintas concepciones del Derecho y a los modelos de la judicatura de modo que los tres aspectos en los que se desglosa la expresión: «los jueces crean Derecho», aunque permiten y aconsejan una distinción conceptual a efectos de clarificar su significado, se hallan involucrados necesariamente en el desenvolvimiento de la experiencia jurídica.

\section{APROXIMACIÓN OSTENSIVA: EL ÁMBITO ESPACIAL DEL «JUZGAR»}

«Las palabras son símbolos que —en opinión de J. L. BORGES- postulan una memoria compartida» ${ }^{17}$. La palabra «juzgar» simboliza la memoria y el presente colectivos, que postulan una pluralidad de significaciones en las que se manifiesta la multivocidad de este concepto.

En el apartado anterior se ha tenido ocasión de comprobar la diversidad de perspectivas, algunas de ellas antagónicas, que dimanan de una de las acepciones del término «juzgar»: la que hace referencia a su condición de fuente del Derecho. Esa acepción, la más problemática y debatida, no agota los significados de uso de la expresión «juzgar». A la pregunta: ¿qué es «juzgar»? se puede contestar a partir de definiciones ostensivas, por denotación o extensión, mostrando una serie de ejemplos de objetos o cosas de los que puede predicarse que son o que tienen que ver con la actividad de juzgar. Así, una posible respuesta a dicha cuestión consistiría en exhibir o apelar a objetos tales como: la sede de un juzgado, de un Tribunal de una Audiencia o del propio Tribunal Supremo, para indicar que esos edificios son manifestaciones de la actividad juzgadora.

La sede en la que la actividad de juzgar se celebra es un edificio que posee una estructura determinada. Un edificio es siempre un espacio arquitectónico acotado, sepa-

17 J. L. Borges, El libro de arena, 11. ${ }^{a}$ reimp., Madrid, Alianza, 1993, p. 37. 
rado y distinto de otros espacios. $\mathrm{Al}$ acotar el espacio, se le da una determinada forma, que organiza los materiales y su propia estructura en función de una finalidad. Por eso, en la forma o disposición interior de un edificio se puede discernir cuál es su peculiar finalidad. La forma interior de un cuartel, de una iglesia, de una estación de ferrocarril, de un edificio de viviendas o de un juzgado, son distintas, en la medida en que son medios espaciales o arquitectónicos encaminados al desarrollo de fines diferentes. Los elementos espaciales de un edificio tienen un carácter instrumental en relación con los fines que en él se persiguen. Lo más característico del interior de un juzgado o corte de justicia es que al margen de determinados elementos funcionales (pasillos, despachos, escalinatas...), posee una o varias salas divididas en dos grandes ámbitos: el estrado, en el que desarrollan su cometido específico unos actores cualificados (jueces, ministerio fiscal, partes acusadoras y acusadas, testigos, peritos, jurados...), y una sala para los espectadores que presencian el desarrollo del proceso. Esto determina que mientras los actores desempeñan y representan un papel especialmente intenso, es decir, activo, el público que desde el espacio de la sala presencia el desenvolvimiento del proceso, asume una función pasiva. En definitiva, el ámbito espacial que sirve de escenario al juicio, tiene unas características propias y engendra, unas representaciones mentales que permiten asociar la noción del proceso judicial con unos determinados edificios ${ }^{18}$.

Ese intento de ofrecer una respuesta a lo que significa juzgar a partir de su identificación con el ámbito espacial en el que el juicio se desarrolla, se realiza a través de lo que se ha denominado supra definiciones ostensivas. Las definiciones ostensivas (del latín ostendere, que significa mostrar), tienen a su favor la fuerza de su evidencia, de operar con realidades experienciales y tangibles y no sobre meras elucubraciones teóricas. Este procedimiento definitorio no se halla exento de algunos riesgos y limitaciones. Porque, las definiciones ostensivas se basan en uno, o en una serie de ejemplos sin que su alcance pueda extenderse arbitrariamente más allá de los mismos. Ello condiciona las pretensiones de generalidad de este método definitorio. Ya que, en efecto, el repertorio de cosas, o sea, de espacios físicos o edificios relativos al «juzgar» que aquí, a modo de ejemplo, se apuntaban, no es cerrado. De ahí, que no escape a la observación más superficial el carácter incompleto del inventario. De otro lado, lo que justifica la relación entre esas muestras o experiencias ostensivas de cosas que son o tienen que ver con el juicio es la presencia en todas ellas de notas o propiedades referidas al concepto de lo que es un proceso judicial. Pues resulta evidente que esas sedes o edificios judiciales, precisamente se relacionan con la noción de juzgar, en la medida en que existe una idea previa de aquello en lo que un juicio consiste. En otros términos, en contra de lo que parece evocar, la evidencia ostensiva no es un prius, sino un posterius; no constituye el antecedente, sino la consecuencia de proyectar sobre determinados segmentos de la experiencia un concepto o idea previamente establecido o, al menos, intuido. En suma, la evidencia sobre la que reposan las definiciones ostensivas no es algo que surja espontáneamente, sino el resultado de un determinado proceso reflexivo, sea o no consciente ${ }^{19}$.

18 Estimo de interés establecer una analogía entre el ámbito espacial del juicio y las sugerentes observaciones que sobre la arquitectura del teatro avanza J. ORTEGA Y GASSET, en su ensayo «Idea del teatro», en Obras completas, cit., vol. 7, pp. 441 y ss.

19 Cfr. A. E. PéreZ LuÑo, Teoría del Derecho. Una concepción de la experiencia jurídica, con la colab. de C. Alarcón, R. González-Tablas y A. Ruiz de la Cuesta, 7. ${ }^{a}$ ed., Madrid, Tecnos, 2008, pp. 29 y ss. 


\section{LA ACCIÓN DE JUZGAR Y SUS DIMENSIONES}

En las reflexiones que anteceden se ha tratado de acotar el ámbito significativo del juicio. Las diferentes posturas doctrinales y soluciones normativas de los sistemas jurídicos sobre el papel de la función judicial en relación con las fuentes del Derecho, ha permitido una aproximación a algunos de los elementos caracterizadores de la propia noción de juzgar. Asimismo, la aproximación ostensiva al significado de juzgar, ha contribuido a perfilar las representaciones que a ese concepto se asocian. Estas dos perspectivas de enfoque responden a un doble interrogante que, convencionalmente, puede denominarse funcional y estructural. La pregunta funcional se expresa así: «¿para qué sirve juzgar?» y se contesta en las múltiples tesis sobre la función creadora de la judicatura. La cuestión estructural alude a: «¿dónde acontece la función de juzgar?» y se explica con la referencia a las sedes o establecimientos donde se celebra el juicio. Queda, no obstante, por plantear una tercera pregunta, que afecta a un tema radical, que puede calificarse de ontológica y quedar formulada en estos términos: «¿qué es juzgar?». Se trata de discernir los elementos constitutivos de esa acción humana en la que el juicio se explicita, cuestión que será abordada aquí.

Conviene no resbalar sobre un aspecto que, aunque en apariencia pueda parecer trivial, es de la máxima importancia. Se trata de que el juicio es un acto humano. Afirmar esto supone una cierta conquista en la evolución de la cultura jurídica. Implica sustraer la acción de juzgar de cualquier connotación mítica, mágica o religiosa. A partir de un determinado desarrollo histórico de la experiencia jurídica, el juicio no se hace depender del azar, de hechos fortuitos, de causas exotéricas inefables o de una voluntad presunta de los dioses. Deja de ser el producto de oráculos, cuyo sentido se atribuye a sibilas o miembros de una casta sacerdotal, en régimen de monopolio.

En los sistemas jurídicos modernos: «la labor de los jueces —en palabras de G. R. CARRIÓ - no se desarrolla en el misterio sino a la vista de todo el mundo, y constituye un aspecto central del funcionamiento de cualquier sociedad organizada. Los miembros de la magistratura no se reclutan entre los iniciados de alguna secta esotérica... los fallos judiciales se publican...» ${ }^{20}$. Si se parte de esa naturaleza inequívoca y específicamente humana del juicio, convendrá clarificar los elementos básicos que en la misma se involucran. En este sentido, cabe establecer que la acción de juzgar se desglosa en tres procesos que tienen que ver con actividades básicas del quehacer humano: la percepción, la intelección y la decisión.

\subsection{El acto de juzgar como percibir}

Como otras actividades propias del desarrollo de la vida humana, la acción de juzgar se explicita a través de determinadas funciones o expresiones de los sentidos. En los sistemas jurídicos del pasado y del presente hallamos continuas referencias a esa dimensión del proceso judicial manifestada a través de percepciones y expresiones sensoriales.

20 G. R. CARRIÓ, «Los jueces crean Derecho», cit., pp. 80-81. 
Constituye un dato insoslayable de la acción de juzgar su referencia a las percepciones sensoriales de la vista y del oído, así como a la expresión oral de ideas o sentimientos. En las normas procesales, de los distintos sectores del ordenamiento jurídico, aparecen constantes referencias a esos aspectos sensoriales. Así, con relación a la componente visual del proceso, pueden reseñarse, sin pretensión alguna de exhaustividad, remisiones tales como: celebración de vistas, señalamiento de vistas, suspensión de vistas, inspección ocular, visto para sentencia... A la percepción auditiva del juicio se alude en expresiones como: Audiencia, audiencia previa al juicio, audiencia pública, audiencia al rebelde, auditor, oidor... Hacen referencia a la dimensión oral del proceso nociones tales como juicio oral, informes orales, deposición oral, testimonio oral, careo, confesión del procesado y personas civil o criminalmente responsables, concesión de la última palabra al procesado...

En la tradición jurídica romanista, la dimensión perceptiva y expresiva del proceso se ha reflejado en múltiples aforismos y brocardos. Entre ellos, merecen ser reseñados algunos: «Audiatur et altera pars» («Óigase también a la otra parte»); «Exhibere est facere in publico potestatem, ut ei qui agat experiundi sit copia» («Exhibir es presentar ante el magistrado para que el demandante pueda ejercitar su acción»); «Manifesta non indigent demonstratione vel probatione» («Las cosas evidentes no necesitan demostración o prueba»); «Uti lingua nuncupassit, ita ius esto» («Según las palabras pronunciadas, así será el Derecho»); «Quum in verbis nulla ambiguitas est, non debet admitti voluntatis quesito» («Cuando no hay ambigüedad ninguna en las palabras, no debe admitirse cuestión sobre la voluntad») ${ }^{21}$.

Incurriría en un exceso de prolijidad y se apartaría del objeto de estas reflexiones, el intento de una consideración demorada en pormenores sobre las distintas manifestaciones y alcance de la dimensión perceptiva del juzgar. A los efectos de este análisis, estimo que será suficiente aludir a algunos episodios y tesis doctrinales en los que se corrobora esta dimensión del quehacer judicial.

a) Entre los episodios históricos en los que se manifiesta la componente «visual» del juicio, ha adquirido especial celebridad el denominado «juicio de Friné», al que aludieron numerosos clásicos greco-latinos y que en la tradición cultural de occidente ha inspirado diversas manifestaciones pictóricas y escultóricas. Friné era una cortesana que adquirió fama por su belleza escultural (en este caso no se trata de una metáfora, ya que fue la modelo predilecta de Praxíteles) en la Atenas del siglo IV a.C. Inducida por sus admiradores a emular a la diosa Afrodita (la Venus romana), fue acusada de impiedad. Esta acusación poseía notable gravedad hasta el punto de haber determinado el proceso y condena de Sócrates. En el juicio, asumió la defensa de Friné el retórico Hipereides, quien ante la dudosa eficacia de sus argumentos exculpatorios, la exhortó a que se desprendiera de su clámide y mostrara su cuerpo desnudo ante

${ }^{21}$ Cfr. R. Domingo (dir.), J. Ortega y B. Rodríguez-Antolín, Principios de Derecho Global. Aforismos jurídicos comentados, Cizur Menor (Navarra), Thomson-Aranzadi, 2003; J. IGLESIAS REDONDO, Repertorio bilingüe de definiciones, reglas y máximas jurídicas romanas, Madrid, Civitas, 1986; J. Mans, Los Principios Generales del Derecho, Barcelona, Bosch, 1979. En la obra Dichos jurídicos y éticos tradicionales, Madrid, Civitas, 1986, compilados por M. G. MARTínEZ, se recogen numerosas máximas referentes a las percepciones sensoriales del juez. Como ejemplo, puede citarse la siguiente: «Ojos de jueces, lengua de abogado y pies de pleiteante, llevan lo suyo adelante», p. 140. 
el Tribunal. Ante la rotundidad de esta visión los jueces unánimemente decidieron absolver a Friné 22 .

b) En lo que respecta a la dimensión «auditiva» del juzgar resulta del mayor interés la investigación del historiador del Derecho C. PETIT, en su relevante obra Iustitia Gothica. En ella, dedica un capítulo titulado: De audientia indiciali a exponer los principales aspectos que revestía esta dimensión del proceso en el ordenamiento jurídico visigodo. La tarea de juzgar en el ámbito del Derecho visigodo ofrece un relevante ejemplo del carácter nuclear que los aspectos auditivos revisten en el proceso. El desenvolvimiento del sistema procesal visigodo registra una decantación desde su primitivo sesgo popular hacia una progresiva tecnificación. El primero, estuvo personificado en la audiencia pública que representa la asamblea colectiva germánica, con la que se quiere que la auditoría judicial se halle inserta en una atmósfera de auditores populares colectivos. Esta fase será progresivamente abandonada en la medida en que, la penetración del Derecho romano en el visigodo se traduzca en una sustitución de los auditores populares por auditores técnicos (juristas o eclesiásticos), los cuales actuarán como colaboradores del juez y serán designados por él ${ }^{23}$.

La institución del jurado pudiera considerarse como una reminiscencia en los sistemas jurídicos actuales de la dimensión popular de la audiencia en el proceso. No huelga tampoco recordar que la componente auditiva del juzgar representa la otra cara de la oralidad del proceso. Se escucha porque se habla. Lo que se oye en el procedimiento judicial es, por tanto, lo que en él se dice. De ahí, que cualquier reflexión sobre las percepciones sensibles auditivas del juicio tengan como referencia y se prolonguen necesariamente en los aspectos orales del proceso.

c) Compendian la inquietud constante, en los sistemas jurídicos y en la doctrina, por cuanto atañe a la oralidad del proceso, las sugerentes observaciones del profesor M. OliVENCIA, mercantilista de denso prestigio, expuestas en sus estudios sobre: Lenguaje y Derecho. La oralidad del proceso constituye un rasgo distintivo y una garantía jurídica de nuestra tradición cultural. Asumiendo ese significado garantista, la vigente Constitución española prescribe que: «El procedimiento será predominantemente oral, sobre todo en materia criminal» (art. 120.2). Asimismo, se corrobora ese principio constitucional de la oralidad en la Ley Orgánica del Poder Judicial (art. 220.1). Pese a lo dispuesto en esos textos, el profesor OLIVENCIA muestra sus alarmas ante una progresiva suplantación de la oralidad por los procedimientos escritos. «Lo cierto es que la oralidad procesal está en regresión y la oratoria forense, arrumbada en el desván de los trastos inútiles». OLIVENCIA reivindica la importancia del informe forense que es, la principal pieza oratoria del debate procesal. Tal informe se realiza en la vista oral de los procesos penales, en los que lo realiza el fiscal la defensa y, en su caso, la acusación particular. Informes orales que se plantearán también en los supuestos de casación y revisión. No obstante la regresión de la oralidad supone, en opinión de OLIVENCIA, un signo preocupante de la orientación de las vigentes normas procesales del ámbito civil y contencioso-administrativo. Concluye OlivenCIA señalando que: «Estamos asistien-

${ }^{22}$ Cfr. J. M. PÉREZ-Prendes, «El mito de Friné», en Cuadernos de Historia del Derecho, núm. 6, 1999, pp. 211 y ss.

23 C. Petit, Iustitia Gothica. Historia Social y Teología del Proceso en la Lex Visigothorum, Huelva, Publicaciones de la Universidad de Huelva, 2002, pp. 243 y ss. 
do a una crisis de la oralidad, acuciada por el retraso en la Administración de Justicia, pero que tiende a perpetuarse como solución definitiva. Víctima de una justicia tardía y con prisas, el informe de Abogados no sólo se reduce a casos contados, sino, dentro de éstos, a una duración con frecuencia insuficiente, impuesta por la urgencia, que lo convierte en una actuación incómoda para el orador y para el Tribunal y pone en grave riesgo su calidad y su utilidad» ${ }^{24}$.

\subsection{El acto de juzgar como razonar}

Del carácter inequívocamente humano del juicio se desprende que uno de sus rasgos constitutivos deba ser la racionalidad. La razón es la facultad humana por excelencia, aquella que distingue al ser humano de otros seres y le confiere, precisamente, el atributo de la humanidad. Pero una vez admitida la decisiva importancia de la razón en la actividad del juez, se plantea un arduo debate metodológico sobre el tipo de racionalidad al que debe adscribirse la tarea de juzgar. Es un debate que ha discurrido en paralelo al de las ya reseñadas disputas de la ciencia y la filosofía del Derecho en torno a la capacidad creadora del juez. Algunos de los argumentos que aquí se invocan se solapan con los avanzados en aquella polémica, aunque en esta, las posiciones pueden reconducirse a dos. La primera, se halla representada por quienes consideran que el acto de juzgar es una manifestación de racionalidad pura, o sea, una actividad estrictamente lógica a través de la cual el juez es capaz de conocer o identificar la norma aplicable al caso controvertido. Quienes defienden esta tesis, comparan la actividad del juez con un silogismo en el que la premisa mayor está representada por el sistema de fuentes del Derecho; la premisa menor, por las circunstancias del caso enjuiciado; y la conclusión es un acto lógico por el cual el juez, una vez identificada la norma pertinente dentro del sistema de fuentes, la aplica a la solución del caso que es objeto del proceso. Se trata, de un mecanismo que explicita el procedimiento de la subsunción, al que se ha aludido supra. La segunda opción concibe la actividad judicial como expresión de la racionalidad práctica, es decir, la reputa un proceso discursivo tendente a inferir las «buenas razones», argumentos o motivos relevantes tendentes a establecer la norma jurídica más oportuna para resolver el proceso.

La Methodenstreit de la filosofía y la teoría del Derecho en las últimas décadas, ha tenido uno de sus aspectos más relevantes en estas dos tesis opuestas sobre lo que significa juzgar en relación con el ejercicio de la racionalidad judicial.

a) Las teorías propugnadadoras de la posibilidad de aplicar modelos de racionalidad lógico-formal al Derecho, han defendido, con decidido énfasis, la concepción del juicio como un acto de estricta racionalidad.

Estas tesis se basan en los aspectos técnicos del lenguaje jurídico, así como en la coherencia y sistematicidad de los ordenamientos jurídicos. Esta dimensión lógica de los sistemas normativos jurídicos permite proyectar para su conocimiento y aplicación determinadas premisas lógico-formales mediante las que el juez identifica la

${ }^{24}$ M. Olivencia RuIZ, «Lenguaje y Derecho», en sus Escritos Jurídicos, vol. I, Sevilla, Fundación El Monte, 2005, pp. 511 y 515. 
norma aplicable al caso. La función judicial se desarrolla, de este modo, en términos de estricta previsibilidad lógica que redundan en la garantía del valor de la seguridad jurídica ${ }^{25}$.

Las tendencias logicistas sobre el significado de juzgar se han visto potenciadas, en estos últimos años, por la posibilidad de proyectar la informática al Derecho. Tal posibilidad se halla condicionada por las características del lenguaje jurídico. En los sistemas jurídicos evolucionados, el lenguaje normativo ha adquirido un notable grado de precisión, lo que en opinión de los defensores de la proyección de la lógica formal y de la informática al Derecho, constituye un dato que avala y facilita tales aplicaciones. No se pueden ocultar, sin embargo, la existencia de dificultades para hacer del lenguaje jurídico un lenguaje exacto, unívoco y lógicamente riguroso. Esas dificultades no se circunscriben a su componente natural, ya que incluso los conceptos y categorías que integran el lenguaje jurídico técnico, a diferencia de cuanto sucede en las ciencias exactas, no siempre son utilizados en el mismo sentido, aun en el seno de un mismo ordenamiento jurídico, lo que comporta importantes problemas con vistas a su formalización. Un lenguaje técnico se halla integrado por un conjunto de términos dotados de un significado preciso. Esa precisión se logra a través de las consiguientes definiciones, dirigidas a dotar de un sentido unívoco y estricto a los términos de tal lenguaje. Las nociones de «hipoteca», «enfiteusis», «contrato», «licitud»... son algunos de los términos técnicos del lenguaje jurídico. Pero no todas las expresiones del lenguaje técnico del Derecho tienen un significado exclusivamente jurídico. Abundan en el lenguaje jurídico supuestos de polisemia (acción, cuadrilla, capacidad, persona...) en los que una misma palabra podrá pertenecer al lenguaje natural o jurídico según su contexto de uso.

La lógica deóntica, más allá de la pluralidad y heterogeneidad de sus acepciones, implica la posibilidad de extender las inferencias lógicas no sólo a las descripciones, sino a las prescripciones; es decir, permite construir una lógica de normas. En este sentido, el ordenamiento jurídico representa el contexto coherente y sistemático en cuyo seno pueden establecerse un sistema de conexiones, deducciones y decisiones lógicas. Todo ello, es muy relevante para la informatización del lenguaje jurídico en un doble sentido: porque a mayor estructuración lógica del lenguaje jurídico, será mas fácil su formalización informática; y porque la posibilidad de proyectar reglas lógicas sintácticas de las normas permite facilitar las operaciones del ordenador. No en vano, las computadoras no utilizan conceptos semánticos, sino relaciones sintácticas. Los operadores deónticos (mandado, prohibido y permitido) posibilitan en definitiva, establecer relaciones de compatibilidad, coherencia y deducción dentro del contexto del ordenamiento jurídico, que pueden ser formalizadas en lenguaje informático.

Al promediar la década de los setenta del pasado siglo, se conforma uno de los sectores más dinámicos y en constante evolución de la Informática jurídica metadocumental o decisional, el que se refiere a la aplicación al Derecho de la inteligencia

${ }^{25}$ Cfr. A. E. PÉREz LuÑo, La seguridad jurídica, cit., pp. 78 y ss y 133 y ss.. Para una panorámica general de los distintos modelos de proyección de la lógica formal a la argumentación jurídica, vid. M. ATIENZA, El Derecho como argumentación, Barcelona, Ariel, 2006, pp. 109 y ss. Asimismo, ha elaborado una exposición de las distintas concepciones formalistas del Derecho: F. Llano AlONSO, El formalismo jurídico y la teoría experiencial del Derecho, con Prólogo, de A. E. Pérez LuÑo, Valencia, Tirant lo Blanch, 2009, pp. 32 y ss. 
artificial (IA) y los sistemas expertos (SE). La inteligencia artificial alude al conjunto de actividades informáticas que si fueran realizadas por el hombre se considerarían producto de su inteligencia. La propia amplitud de estas operaciones que abarcan desde la comprensión de lenguajes naturales, el reconocimiento de imágenes o sonidos, hasta una amplia y diversa gama de juegos y simulaciones, han determinado una necesidad de acotar y delimitar su ámbito. A ello también ha contribuido la contradicción que supone predicar de entidades ajenas al hombre el rasgo humano por excelencia, o sea, la inteligencia. De ahí que hoy se aluda preferentemente a lo que es el sector más importante de la inteligencia artificial el que se refiere a los sistemas expertos. Tales sistemas incorporan, de una manera práctica y operativa, el conocimiento que posee un experto en la materia de que se trate. Consisten en programas que reproducen las actuaciones que ha previsto el experto que los diseña. Entre los sistemas expertos más notorios de nuestros días se encuentran los dirigidos al diseño artístico o arquitectónico, la localización de yacimientos minerales y el diagnóstico médico. El paralelismo entre el diagnóstico clínico y el dictamen o razonamiento del juez han propiciado una copiosa bibliografía sobre experiencias de aplicación de los SE a la actividad judicial. Se indica que al igual que el médico dictamina en función de alojar los síntomas de la enfermedad en un cuadro de patologías, el juez mediante el silogismo de la subsunción atribuye a unos hechos tipificados las consecuencias jurídicas previstas en la norma. En función de ello han proliferado en estos años una serie de proyectos y prototipos de sistemas expertos jurídicos (SEJ) en materias tales como liquidaciones tributarias, cálculo de indemnizaciones por accidentes laborales o de tráfico, predicción de las consecuencias jurídicas de impactos medioambientales, condiciones de adquisición de la nacionalidad y Derecho de familia, en concreto, matrimonio y divorcio. Estos sistemas más que a suplantar la racionalidad judicial, como indebidamente pretendieron algunos radicales ingenuos de la informática jurídica, se plantean hoy como medios auxiliares y, en cierto modo, confirmadores de la actividad lógica del juez ${ }^{26}$.

b) Pionero en la restauración del interés jurídico por la racionalidad práctica, así como por sus repercusiones en el quehacer judicial, fue T. VIEHWEG, quien concibe la «tópica» como el método dialógico que orienta el razonamiento del juez hacia la decisión de los casos, o problemas concretos, en los que se expresa el Derecho ${ }^{27}$. Deben también mencionarse los estudios sobre la nueva retórica debidos a C. PERELMAN, tendentes a mostrar la estructura argumentativa del razonamiento judicial ${ }^{28}$; así como la revalorización de la razón práctica, denominada por L. RECASÉNS SICHES «logos de lo razonable», en la interpretación y aplicación del Derecho por parte de la judicatura ${ }^{29}$.

26 Cfr. A. E. PÉREz LuÑo, Cibernética, Informática y Derecho. Un análisis metodológico, Bolonia, Publicaciones del Real Colegio de España, 1976, pp. 83 y ss.; id., Manual de informática y Derecho, Barcelona, Ariel, 1996, pp. 179 y ss.; id., Ensayos de Informática Jurídica, México, Fontamara, 1996, pp. 107 y ss.; id., ¿Ciberciudadaní@o ciudadaní@com?, Barcelona, Gedisa, 2004,pp.57 y ss.

27 Th. Vienweg, Topik und Jurisprudenz, München, Beck, 1953 (de esta obra existe trad. cast. de L. DíEZPiCAzo, Tópica y jurisprudencia, Madrid, Taurus, 1964).

28 Ch. Perelman, Traité de l'argumentation. La nouvelle rhétorique, en col. con L. OlbreCHTS-TyteCA, Bruxelles, Editions de l’Université de Bruxelles, 1970.

29 L. RECASÉns Siches, Nueva filosofía de la interpretación del Derecho, México, Fondo de Cultura Económica, 1956; id., Experiencia jurídica, naturaleza de la cosa y Lógica «razonable», México, Fondo de Cultura Económica y UNAM, 1971. 
La relevancia general de la racionalidad práctica en los sistemas normativos ha sido objeto de un estudio de J. RAZ, en el que concibe las «razones» (reasons) como relaciones entre hechos y personas, siempre que se trate de hechos con proyección normativa en cuanto que determinen la actuación debida. RAZ, más que de la filosofía práctica valorativa tendente a mostrar los valores que deben perseguirse y las razones orientadoras de la acción, prefiere centrar su atención en el análisis práctico-conceptual de categorías tales como la del valor, norma, acción y de la naturaleza de las reglas de inferencia que gobiernan el razonamiento práctico. Para ello, propugna una filosofía general de la razón práctica, que estudiaría conceptos comunes a las diversas disciplinas prácticas (Derecho, moral y política), tales como los de regla y sistema normativo. Corolario de tal premisa es su convicción de que es posible y necesario desarrollar una lógica unificada de los conceptos normativos, y que la parte básica de esa lógica no es la lógica deóntica, sino la lógica de las razones para la acción, entre las que ocupan un lugar cualificado las que tienden a dirigir la acción de juzgar ${ }^{30}$.

En el marco de tales inquietudes es también digno de mención el esfuerzo de Josef EsSER con referencia a la necesidad de que el juez tenga presentes las expectativas de la colectividad para que el resultado de la función hermenéutica, que posee una insoslayable dimensión práctica, goce de un amplio consenso social ${ }^{31}$. J. HART ELY insistirá, a su vez, en la necesidad de que la decisión judicial se vea limitada por la exigencia de ponderar los intereses de los afectados, sobre la base de una consideración igual de sus personas ${ }^{32}$.

En la dimensión institucional de las pautas de racionalidad práctica de la función judicial han hecho especial hincapié N. MACCORMICK y O. WeINBERGER. Los sistemas jurídicos contemporáneos requieren un alto grado de racionalidad tanto en su estructura normativa, como en los procedimientos de aplicación del Derecho. La racionalidad práctica desempeña una importante función de garantía de la adecuación de las decisiones judiciales a consecuencias socialmente deseables y racionalmente fundadas. Mediante el ejercicio de la racionalidad práctica, los jueces tienden a apoyar sus decisiones en criterios universalizables; es decir, rebasan objetivos particulares para perseguir aquellos valores generalizados e institucionalizados en la práctica social, que legitiman la observancia del Derecho ${ }^{33}$.

c) Especial mención merece el empeño de R. ALEXY por sugerir reglas y procedimientos tendentes a garantizar la racionalidad de la argumentación jurídica, ofreciendo un cauce mediador entre las dos posturas hasta aquí reseñadas. ALEXY pretende evitar, de este modo, que las ineludibles valoraciones del juez degeneren en juicios de valor subjetivos y arbitrarios. La referencia a las normas materiales y procesales aplicables al caso, la obligada consideración de los precedentes, así como las pautas orientadoras de

30 J. Raz, Practical Reason and Norms, London, Hutchinson, 1975 (de la 2. ${ }^{a}$ ed. de esta obra que data de 1990 existe trad. cast. de J. Ruiz Manero, Madrid, Centro de Estudios Constitucionales, 1991).

31 J. EsSER, Vorverständnis und Metodhenwabl in der Rechtsfindung, Frankfurt a.M., Atheneum, 1970.

32 J. HarT Ely, Democracy and Distrust. A theory of Judicial Review, Cambridge (Mass.) y London, Harvard University Press, 1980.

33 N. MACCormick y O. Weinberger, An Institutional Theory of Law, Dordrecht, Reidel, 1986. Del Capítulo XI de esta obra sobre Los límites de la racionalidad en el razonamiento jurídico, existe trad. cast. de M. Atienza y J. Ruiz Manero incluida en el vol. a cargo de J. Betegón y J. R. DE PÁramo, Derecho y Moral. Ensayos analíticos, Barcelona, Ariel, 1990, pp. 9 y ss. 
la Dogmática jurídica institucionalmente cultivada, constituyen el horizonte en el que se proyecta la racionalidad práctica en el Derecho.

Quizás el mérito principal de las investigaciones de AlEXY resida en su esfuerzo por establecer un acercamiento entre la argumentación jurídica a partir de la racionalidad práctica y el análisis lógico y lingüístico del razonamiento judicial. AlEXY comparte con los teóricos de la argumentación la idea de que la racionalidad jurídica no puede reducirse a esquemas de la lógica formal. No obstante, la racionalidad de la argumentación jurídica no deja de ser una forma de «racionalidad», que debe obedecer a premisas de corrección y rigor. El elemento básico para conseguirlo es el procedimiento.

El razonamiento del juez no responde al azar o a la arbitrariedad, sino a «razones» que actúan como modelos justificativos de la creación, la interpretación y la aplicación de normas. Esas justificaciones no sólo se basan en factores estáticos (la conformidad de las premisas con el contenido de reglas jurídicas positivas o meta positivas -Derecho natural-; o la estricta deducción entre las premisas y sus consecuencias...); sino principalmente en un elemento dinámico: el procedimiento argumentativo.

R. ALEXY ha acogido, desarrollado y proyectado al Derecho las tesis sobre el discurso práctico y la teoría consensual de la verdad debida a J. HABERMAS. Según AlEXY un discurso práctico es racional cuando satisface las condiciones de una argumentación práctica racional. Cuando estas condiciones se cumplen, el resultado del discurso es correcto. La teoría del discurso es, por tanto, una teoría procedimental de la corrección práctica. Las condiciones que garantizan la racionalidad del procedimiento del discurso son resumidas por ALEXY en un sistema de reglas que guían la actividad de la racionalidad práctica. Estas reglas responden a una doble exigencia:

1) Las que garantizan la corrección estructural de los argumentos y que imponen, entre otras cosas, su no contradicción, la claridad ligüístico-conceptual, la veracidad de las premisas empíricas utilizadas, la exhaustividad deductiva de los argumentos, la consideración de las consecuencias, la valoración comparativa de los argumentos.

2) Las que garantizan la imparcialidad del procedimiento argumentativo y que hacen referencia al reconocimiento del Derecho a participar en el discurso en condiciones de libertad y de igualdad (cualquier persona capaz puede intervenir en el discurso, plantear sus puntos de vista, deseos y necesidades; a ningún dialogante se le puede impedir que ejercite sus facultades reconocidas en las reglas del discurso, mediante una coacción establecida, exterior o interior al discurso) ${ }^{34}$.

Las tesis de R. Alexy, en lo que conciernen al significado de la labor judicial, permiten, a mí entender, inferir una doble consecuencia:

1. a) Que la teoría de la argumentación judicial ha supuesto, en cierto modo, un desplazamiento desde la hoy cuestionable coherencia del ordenamiento jurídico, a la coherencia, en términos de racionalidad discursiva, de las decisiones jurisprudenciales.

34 R. AleXY, «Die Idee einer prozeduralen Theorie der juristischen Argumentation», en Rechtstheorie, núm. 2, 1981, pp. 178 y ss.; id., Theorie der juristischen Argumentation, Frankfurt a.M., Suhrkamp, 1978. (trad. cast. de M. ATIENZA e I. EsPejo, Teoría de la argumentación jurídica, Madrid, Centro de Estudios Constitucionales, 1990), pp. 213 y ss. Cfr. M. ATIENZA, Las razones del Derecho. Teorías de la argumentación jurídica, Madrid, Centro de Estudios Constitucionales, 1991, pp. 177 y ss. 
2. ${ }^{a}$ ) Que la teoría de la argumentación racional de ALEXY no es ideológicamente neutral. Los presupuestos del procedimiento discursivo son la libertad y la igualdad, o sea, los valores básicos del Estado de Derecho y a su vez, la teoría del consenso obtenido a través de la argumentación racional constituye el fundamento legitimador de la legalidad del Estado de Derecho. De este modo, se advierte una cierta circularidad en esta concepción argumentativa: la argumentación exige la presencia de determinados derechos para garantizar su propia racionalidad e imparcialidad; y los derechos fundamentales requieren de la argumentación para poder ser interpretados y aplicados por los jueces a las situaciones concretas ${ }^{35}$.

Las tesis de ALEXY han sido un fértil estímulo para la superación de las doctrinas propugnadoras de una fractura entre las dimensiones lógico-formal y práctica del razonamiento jurídico. La rebelión, surgida al promediar el pasado siglo, contra los excesos del logicismo formalista en el Derecho pagaron, a su vez, tributo al exceso. El ardor polémico con el que denunciaron la unilateralidad de los empeños teóricos que reducían todo el razonamiento jurídico a un conjunto de procesos y categorías lógicoformales, les condujo a negar los ingredientes lógicos y sistemáticos que insoslayablemente integran también la argumentación de los juristas. Hoy se considera más ajustado a la realidad reconocer la interdependencia de esas dos dimensiones y su presencia necesaria y conjunta en una visión comprensiva de los argumentos jurídicos.

Síntoma ejemplar de esos nuevos rumbos metodológicos es el enfoque de $\mathrm{M}$. ATIENZA, que ha trazado una completa síntesis de los procesos lógico-formales, materiales y pragmáticos que conforman la argumentación jurídica. Sin desconocer la relevancia de estos últimos, ATIENZA propone una evaluación de las aportaciones de la lógica formal al razonamiento jurídico que persigue evitar las dos polaridades extremas, e igualmente insatisfactorias, respecto a la incidencia de la lógica formal en el Derecho. La primera de ellas, se halla representada por las tesis que postulan la posibilidad de formalizar absoluta e integralmente todos los procesos discursivos conformadores de los argumentos jurídicos. La segunda, respondería a la actitud de quienes, como se ha tenido ocasión de reseñar supra, infravaloran o niegan cualquier proyección lógicoformal en la esfera de los razonamientos jurídicos.

Estima ATIENZA que contra lo que hay que estar en la argumentación jurídica no es obviamente contra la lógica, lo que sería caer en un absurdo, sino contra sus pretensiones imperialistas. El análisis lógico de los razonamientos jurídicos no es una labor que pueda considerarse ya finalizada. Queda abierta la tarea de una proyección de la lógica sobre la pluralidad de los enunciados jurídicos, que dé cuenta de la variedad de elementos que integran una concepción amplia del Derecho. Invoca ATIENZA el paralelismo, aducido en ocasiones, entre la gramática y la lógica. Para escribir bien no basta con conocer las reglas de la gramática, pero conocerlas es de gran ayuda. De modo análogo, el jurista que tiene que argumentar en el Derecho, no será un buen jurista

35 R. AlEXY, Theorie der Grundrechte, Frankfurt a.M., Suhrkamp, 1986, de la que existe versión cast. de E. GARZÓn VALDÉs, revisada por R. ZimmerLing, Madrid, Centro de Estudios Constitucionales, 1993; id., Begriff und Geltung des Rechts, Freiburg-München, Steiner, 1992, de la que existe versión cast. de J. M. SEÑA, Barcelona, Gedisa, 1994; id., Derechos sociales y ponderación, ed. cast. a cargo de R. GARCía ManRiQue, vol., col., en el que se recogen también colaboraciones de varios autores, Madrid, Fundación Coloquio Jurídico Europeo, 2007. 
simplemente por conocer algo de lógica, pero ese conocimiento es de una inestimable ayuda en determinados contextos.

ATIENZA cifra dichas aportaciones en tres ámbitos:1) Ofrecer esquemas de análisis, que ayudan a ordenar los argumentos y a evaluar, prima facie, su posible bondad. El conocimiento de la lógica contribuye a la claridad de la argumentación. 2) Contribuir a facilitar la interpretación y la conceptualización. La lógica proporciona un lenguaje formal al que poder traducir los argumentos del lenguaje natural. Permite así, dotar a la expresión de los argumentos jurídicos de un lenguaje riguroso, evitando las contradicciones, incoherencias, ambigüedades... Con ello, no quedan resueltos todos los problemas que concurren en la interpretación del Derecho, pero se contribuye a evidenciarlos. 3) Proporcionar un criterio para el control de los argumentos. Para la lógica deductiva, la mayor parte de los argumentos que efectuamos en la vida cotidiana y en la jurídica, son entimemáticos, esto es, no explicitan todas sus premisas. La lógica deductiva es un método que permite detectar las premisas que faltan y controlar la calidad de los argumentos, pues nos lleva a plantearnos la cuestión de hasta qué punto esas premisas implícitas son o no aceptables ${ }^{36}$.

Este enfoque, estimo, que es susceptible de ser proyectado a la esfera de la argumentación judicial. También en ella el razonamiento del juez encuentra un provechoso apoyo en la lógica formal en tres momentos: $1 .^{\circ}$ ) El de la actividad judicial tendente a la elaboración rigurosa, es decir, ordenada, coherente y clara de sus argumentaciones. $2^{\circ}{ }^{\circ}$ El El de la expresión lingüística de esos argumentos, a través de un lenguaje preciso y depurado de términos ambiguos u oscuros... Con ello, se facilita la interpretación del significado de las sentencias. $3^{\circ}$ ) El que concierne a la congruencia interna de las cadenas argumentativas que vertebran el razonamiento judicial y que constituyen el nervio de la motivación de las sentencias.

En la jurisprudencia española, en especial en la del Tribunal Constitucional, al igual que en la de otros Estados de Derecho de nuestro entorno político-cultural, se advierte el preponderante papel que asume la argumentación racional como garantía de la seguridad jurídica de los ciudadanos. En el marco de la amplia, casi constante referencia del TC a la fundamentación racional de sus argumentos y en relación con aspectos que inciden en la argumentación iusfundamental, se pueden distinguir tres postulados básicos:

$1 .^{\circ}$ ) La argumentación racional se considera como requisito básico para la tutela efectiva de los derechos fundamentales. Existe una abundante jurisprudencia en la que expresamente se alude a la motivación, en términos de argumentación racional de las decisiones, como elemento nuclear del Derecho constitucional a la tutela efectiva. Así, nuestro máximo intérprete de la Constitución proclama que: «Es doctrina reiterada de este Tribunal Constitucional que la tutela judicial efectiva, consagrada en el art. 24.1

36 M. ATIENZA, El Derecho como argumentación, cit., pp. 179-180. A partir de las formulaciones De VICO, he propugnado también un planteamiento integrador de las dimensiones lógico-formal y práctica del razonamiento jurídico, en mis trabajos: «Razonamiento jurídico y razonamiento cibernético», en mi libro: Cibernética, Informática y Derecho. Un análisis metodológico, Bolonia, Publicaciones del Real Colegio de España, 1978, pp. 83 y ss.; «Giambattista Vico y el actual debate sobre la argumentación jurídica», en Cuadernos sobre Vico, núms. 5-6, pp. 123 y ss.; «Un modelo histórico de argumentación jurídica: Giambattista Vico», en Revista de Ciencias Sociales, núm. 45, Chile, Universidad de Valparaíso, pp. 15 y ss. 
CE, comprende el Derecho a obtener una resolución fundada en Derecho, como garantía máxima — dada la esencia de la función jurisdiccional — frente a la arbitrariedad e irrazonabilidad en la actuación de los poderes públicos» (STC 131/1990, FJ 1). Doctrina reiterada, entre otras, en la sentencia que sostiene: «La obligación de motivar las sentencias que el art. 120.3 CE impone a los órganos judiciales, puesta en conexión con el derecho a la tutela judicial protegido por el art. 24.1 de la Constitución —entendido como derecho a una resolución jurídicamente fundada-, conduce a integrar en el contenido de esta garantía constitucional el derecho del justiciable a conocer las razones de las decisiones judiciales y, por tanto, el enlace de las mismas con la ley y el sistema general de fuentes, de la cual son aplicación» (STC 14/1991, FJ 2).

2. ${ }^{\circ}$ ) La argumentación judicial se concibe como un ejercicio de racionalidad tendente a evitar decisiones arbitrarias. Un buen número de sentencias de nuestro TC coinciden en exigir una motivación basada en razonamientos argumentativos de las decisiones judiciales, como medio para evitar resultados contradictorios o ilógicos. Ello implica que los jueces deberán justificar racionalmente sus resoluciones y sentencias. Baste como muestra cuanto el TC expresa en los siguientes párrafos: «Es doctrina reiterada de este Tribunal Constitucional que una aplicación de la legalidad que sea arbitraria, manifiestamente irrazonada o irrazonable no puede considerarse fundada en Derecho y lesiona, por ello, el derecho a la tutela judicial... Así ocurre en los casos en los que ... la resolución judicial contiene contradicciones internas o errores lógicos que hacen de ella una resolución manifiestamente irrazonable por contradictoria y, por ello, carente de motivación» (STC 184/1992, FJ 2) ${ }^{37}$.

3. ${ }^{\circ}$ La exigencia de argumentación racional no garantiza el acierto de la decisión judicial. El TC advierte que el procedimiento argumentativo contribuye a que las decisiones judiciales se elaboren según pautas de racionalidad formal, pero sin que ello necesariamente entrañe que el resultado de esas inferencias racionales represente la justicia material. Como ejemplo significativo de esta orientación, puede valer cuanto se indica en la siguiente decisión del TC, en la que se sostiene que «el derecho a la tutela judicial reconocido en el art. 24.1 CE conlleva el derecho a obtener una resolución fundada en Derecho en relación a la pretensión formulada ante el Juez competente, el cual debe aplicar de manera motivada las normas jurídicas aplicables y resolver razonadamente la cuestión que se le plantea, pero el art. 24.1 CE no garantiza el acierto del órgano judicial en cuanto a la solución del caso concreto» (STC 55/1993, FJ 5).

\subsection{El acto de juzgar como decidir}

Existen múltiples actividades humanas en las que se involucran percepciones y razonamientos, sin que las mismas posean relevancia jurídica. Lo que caracteriza el acto de juzgar es el que esas percepciones y razonamientos se dirijan a obtener unas determinadas consecuencias jurídicamente relevantes. Por ello, las sentencias o fallos judiciales se denominan también: «decisiones». El juez, tras percibir determinadas si-

37 Cfr. M. ATIENZA, El Derecho como argumentación, cit., pp. 154 y ss.; R. DE Asís, El juez y la motivación en el Derecho, Madrid, Dykinson, 2005, pp. 77 y ss.; J. MALEM, El error judicial y la formación de los jueces, Barcelona, Gedisa, 2008, pp. 27 y ss.; A. NIETO, El arbitrio judicial, Barcelona, Ariel, 2000, pp. 17 y ss.; L. PRIETO SANCHÍs, Justicia constitucional y derechos fundamentales, Madrid, Trotta, 2003, pp. 175 y ss. 
tuaciones a través de sus sentidos, y tras su pertinente discernimiento racional establece lo que en Derecho procede para resolver un conflicto, reconocer un derecho o imponer una obligación. La decisión judicial exige, por tanto, un acto de voluntad por parte del juez a través del cual se pone fin a un proceso, mediante el establecimiento de lo que en Derecho procede. Fija, de esta forma, la conclusión de una causa y lo que es, en términos procesales, la «verdad jurídica», provisoria o definitiva, según asuma o no la calidad de cosa juzgada ${ }^{38}$.

Sobre el significado histórico y actual de las decisiones judiciales, resulta de innegable mérito la reflexión avanzada por L. RECASÉNS SICHES, quien ofrece una síntesis crítica de alguna de las teorías más relevantes en esta materia. Las doctrinas de T. VIEhWEG, J. Esser, O. BALlWeg, M. Villey, J. STONE... han sido analizadas con atento interés por parte de RECASÉNS para establecer algunas consecuencias de incuestionable calado en esta esfera. Según RECASÉNS, el mérito de estos autores reside en que ofrecen la visión más profunda y más aguda sobre la naturaleza de la decisión judicial, orientada hacia la solución práctica de los conflictos jurídicos.

Existe una buena razón que excluye la posibilidad de que la decisión judicial sea lograda por una inferencia deductiva: quizá ninguna de las reglas usadas por los jueces permita inferir de ella la solución correctamente adaptada al litigio. Las reglas orientadoras de la decisión, en el devenir del proceso, habían sido construidas por obra de los jurisconsultos que trabajaban sobre la base de precedentes, sobre casos más o menos similares, y no sobre el fundamento de principios de la razón pura deducidos de una ley racional supuestamente conocida de antemano. O bien, ninguno de esos precedentes era exactamente idéntico al caso que se debía juzgar. Ahora bien, el Derecho se había definido como la solución concreta apropiada al caso singular, según la naturaleza de éste. Consiguientemente, esta solución no podía ser extraída exclusivamente de la regla, prevista para casos diferentes; y, por eso, era necesario finalmente que la solución tomase en cuenta otras fuentes. El juez no decide solo, como el matemático o como el sabio de gabinete, o como el lógico moderno. La búsqueda de la decisión, se hace por varias gentes. De hecho, es polifónica. En el escenario jurídico donde se forma la solución del Derecho, están necesariamente presentes los abogados de las dos partes, también el representante de la sociedad, es decir el fiscal, los representantes legales de los terceros que pueden tener un interés en el proceso; y el juez, quien resuelve. La luz surgirá del debate entre los alegatos contrarios. En lugar de la invención de leyes abstractas, el Derecho era, en otro tiempo, la controversia, y debe seguir siéndolo.

Las reglas sirvieron como medios para acercarse a la solución definitiva. En el fondo, la solución se desprende de la naturaleza de cada caso concreto. El juez, hoy lo mismo que antaño, no procede por vía de silogismos. Lo que hace es añadir después ficticiamente la apariencia de una forma seudosilogística. Sabemos muy bien que el trabajo efectivo de juez consiste hoy lo mismo que ayer en buscar la solución de Derecho por la vía de la dialéctica; en elegir la regla adecuada entre las reglas legislativas alegadas por los litigantes, reglas que no son concordes y que no constituyen en modo alguno un orden jurídico homogéneo. Consiste, cuando ello es necesario, en ir más allá

38 Sobre la noción de «verdad jurídica» en los supuestos de cosa juzgada, $c f r$. A. E. PÉREz LuÑo, La seguridad jurídica, cit., pp. 115 y ss. 
de la regla legislativa; en forjar nuevas reglas, en pronunciar una sentencia adecuada al caso concreto, el cual es siempre nuevo. Si en la decisión del Derecho por el juez existe siempre esa parte viva e imprevisible, entonces es ilusorio edificar una ciencia axiomática del Derecho. RECASÉNS sostiene que hay menos seguridad cuando se vive dentro de la ficción de un régimen deductivo, que cuando se reconoce, a todas luces, el procedimiento de la controversia; y cuando se tiene conciencia de que el tema medular de la decisión judicial es el ejercicio de la dialéctica, o arte del diálogo o del debate ${ }^{39}$.

He demorado en pormenores la exposición del planteamiento de RECASÉNS por entender que ofrece una visión paradigmática de los principales aspectos históricos y actuales de la decisión judicial. Debo, no obstante, puntualizar algunos asertos de ese enfoque que no me siento inclinado a suscribir. Porque el temor que a RECASÉNS, en su etapa de madurez, le suscita cualquier recaída en el logicismo o en el formalismo jurídico, le lleva a un error táctico, que es también un error substancial. La pretensión de erradicar de la decisión judicial cualquier atisbo de logicismo formalista le conduce a confundir los términos del problema. Pues de la naturaleza concreta que es propia de cualquier decisión judicial, por tratarse de un acto de aplicación individualizada de reglas generales y abstractas al caso controvertido, no se deriva que tal proceso sea sólo un acto de voluntad de carácter vital o experiencial, ajeno a cualquier inferencia lógica o elaboración sistemática. De cuanto hasta aquí se ha expuesto se desprende que la decisión judicial es una actividad subsiguiente a determinadas percepciones sensitivas, así como a determinados ejercicios de racionalidad. Desgajar la decisión judicial de su previa fundamentación racional equivale a convertir la voluntad del juez en voluntarismo; su decisión en decisionismo. El afán por sustraer el acto de voluntad en que la decisión del juez consiste de cualquier presupuesto y fundamento lógicos corre el riesgo de desembocar en el extremo contrario y, por tanto, en un extremismo: el del arbitrio judicial (cuestión a la que se aludirá infra).

Debe también reseñarse que, en fecha más reciente, algunas de las inquietudes expresadas por RECASÉNS en torno a la decisión judicial, han hallado nuevas formulaciones y planteamientos renovados. Entre los mismos, es preciso aludir a una tesis de R. DwORKIN que ha suscitado amplio debate y polémica. La teoría de la aplicación judicial del Derecho, que DwORKIN, sostiene, parte de un objetivismo ético-jurídico entendido como posibilidad de derivar principios materiales válidos para solucionar los procesos judiciales a partir de una supuesta, «única respuesta correcta»: One right answer (frente a la tesis escéptica de que «no existe respuesta correcta»: No right answer) de los casos difíciles, la teoría de DwORKIN imagina un mítico juez Hércules, que es capaz de descubrir la «única» respuesta jurídicamente adecuada a la solución de cada caso ${ }^{40}$.

Esta teoría de la actividad judicial choca con algunos de los presupuestos metódicos e ideológicos más arraigados en el pensamiento jurídico contemporáneo. Porque, hoy se reivindica, desde diferentes enfoques, la apertura y pluralismo metódico, frente a cualquier tipo de monopolio metodológico. Lo que lleva a concebir los procesos hermenéuticos del Derecho como una instancia crítica, dinámica y abierta a una serie

39 L. RECASÉNS Siches: Experiencia jurídica, naturaleza de la cosa y Lógica «razonable», cit., pp. 424 y ss.; id., Nueva filosofía de la interpretación del Derecho, pp. 270 y ss.

${ }^{40}$ R. Dworkin, Taking Rights Seriously, cit., pp. 116 y ss. 
de alternativas y a un pensamiento de posibilidades (Möglichkeitsdenkens), que no sería sino el correlato metódico de la apuesta política en favor de una sociedad abierta y pluralista ${ }^{41}$.

En relación con las decisiones judiciales, supone una implícita crítica a la tesis de DwOrKIN, la perspectiva metodológica del enfoque de J. ELSTER. En su obra Juicios salomónicos ha insistido en las dificultades de una decisión estrictamente racional de los procesos judiciales. Ello se debe a la imposibilidad de hallar una única solución racional de determinados conflictos y/o y a la imposibilidad de que la pretendida solución racional pueda realizarse ${ }^{42}$. Se infiere de ese planteamiento la propia ambigüedad que entraña la pretensión de una única decisión correcta. La idea de «corrección» será distinta desde las diferentes partes que concurren en el proceso, o desde la propia defensa del interés público que compete al Ministerio Fiscal. De otro lado, esa idea de «corrección» conducirá a diferentes decisiones o fallos según se la conciba desde el parámetro de los principios o desde el de las consecuencias, desde premisas deontológicas o utilitarias.

Una interesante aportación reciente al significado de la decisión judicial se debe a la teoría de las normas jurídicas propuesta por H. HART. Como es sabido este prestigioso teórico del Derecho inglés distingue entre lo que denomina: normas primarias, que son aquellas que imponen deberes; y normas secundarias, que son las que establecen determinados poderes de actuación. Estas últimas cumplen una importante función tendente a garantizar seguridad jurídica, las normas que HART denomina: «normas de adjudicación». Estas normas, en una sociedad evolucionada se atribuyen a unos órganos con facultades para determinar si los comportamientos son o no conformes a las normas primarias y para ejercer eficazmente la presión contra quienes incumplen las normas. Por ello, estas normas responden a la necesidad de crear unas normas secundarias que establezcan un procedimiento para decidir cuándo se transgreden las normas primarias y cómo se materializa la reacción social contra el transgresor. Contra la inseguridad en la aplicación de las normas, el remedio es una regla (secundaria) de adjudicación. Se infiere de la tesis de HART, la atribución a los jueces de una sociedad moderna de un papel conformador del sistema jurídico al contribuir a través de sus decisiones a adjudicar las consecuencias jurídicas pertinentes a las actuaciones cívicas que poseen trascendencia para el Derecho ${ }^{43}$.

La tesis de HART posee la virtualidad de incidir en el necesario entronque de la decisión judicial en el sistema normativo. Tal exigencia se manifiesta en un doble plano: de una parte, los poderes de adjudicación del juez proceden del sistema de fuentes normativas vigentes en un determinado ordenamiento jurídico; de otra, la potestad judicial de adjudicar facultades y obligaciones, se desarrolla a partir de las normas de procedimiento y las normas substantivas vigentes en el ordenamiento jurídico de que se trate. Esta observación resulta imprescindible para situar la decisión judicial en sus debidos términos. En efecto, la crítica al logicismo de la decisión judicial, no

${ }^{41}$ Cfr. A. E. PÉREZ LuÑo: El desbordamiento de las fuentes del Derecho, cit., pp. 32 y ss.; Derechos humanos, Estado de Derecho y Constitución, cit. pp. 255 y ss.

${ }^{42}$ J. ElSTER, Juicios salomónicos. Las limitaciones de la racionalidad como principio de la decisión, trad. cast. C. GARDINI, Barcelona, Gedisa, 1995, pp. 11 y ss.

${ }^{43}$ H. HART, The Concept of Law, cit., pp. 132 y ss. 
debe confundirse con la impugnación del carácter normativo de tal decisión: una cosa es que la decisión del juez no se traduzca en un acto de estricta lógica formal y otra diferente que ese acto decisorio se realice al margen de las normas del sistema jurídico en el que se produce. De igual modo, tal como se tuvo ocasión de apuntar supra, el debate sobre la significación creadora de las decisiones judiciales, no significa situar las sentencias al margen del ordenamiento jurídico. Precisamente ese debate representa la manifestación de una pluralidad de concepciones sobre el sentido del Derecho y el concepto del Derecho.

De lo anterior se infiere la negación de cualquier tentativa de identificar la decisión judicial con la arbitrariedad decisionista del juez. Para no incidir en los meandros doctrinales de la vieja controversia sobre la procedencia y alcance del arbitrio judicial, que supondría rebasar los límites de esta reflexión, estimo de interés recordar un texto en el que de forma concluyente y diáfana se expresa la incompatibilidad de cualquier decisión judicial arbitraria con el Estado de Derecho. En el Catecismo político, arreglado a la Constitución de la Monarquía española, los liberales gaditanos en su afán de promover la pedagogía cívica del texto doceañista dedicaron la Lección XIV de esa obra a la temática: «De la administración de justicia». En dicho capítulo y respondiendo a la pregunta de si es procedente que el juez pueda actuar contra cualquier ciudadano a su antojo, se responde en estos términos inequívocos: «Si los jueces tuviesen esta facultad, sería inútil la división de potestades, pues la arbitrariedad que se evita con ella en el Rey, se trasladaría a los jueces, y entonces en lugar de un solo déspota tendríamos tantos déspotas como jueces» ${ }^{44}$.

\section{CONCLUSIÓN: LAS TRES DIMENSIONES DEL JUZGAR Y EL TRIDIMENSIONALISMO JURÍDICO}

Los tres aspectos o dimensiones en los que es posible desglosar conceptualmente la actividad de juzgar, se hallan necesaria e inescindiblemente involucrados en la experiencia jurídica del proceso. Las distinciones analíticas avanzadas en los apartados anteriores han tendido a clarificar, en el plano metódico-jurídico, los distintos momentos y actividades que concurren en la tarea de juzgar. No parece ocioso insistir ahora, al retomar el hilo conductor y concluir estas consideraciones, en la necesidad de concebir el «juzgar» como la síntesis de unas actividades de percepción, de argumentación racional y de decisión. La falta de cualquiera de estas dimensiones determinará el carácter incompleto o defectuoso del juicio. Su concurrencia en el proceso podrá, no obstante, acomodarse a los diferentes supuestos que se han reflejado en los distintos parágrafos de esta investigación.

La triple dimensión del juzgar invita a establecer nexos de analogía respecto a la concepción del tridimensionalismo jurídico. La experiencia jurídica posee una significación compleja y problemática que no consiente fáciles y artificiosas simplificaciones. Toda sociedad, con independencia de su amplitud y grado de evolución, precisa regu-

${ }^{44}$ Catecismo político, arreglado a la Constitución de la Monarquía española, se cita por la ed. facsímil a cargo de J. Calvo (a partir del texto reimpreso por Quincozes, Málaga, 1820), Málaga, Facultad de Derecho de la Universidad de Málaga, 1992, p. 64. 
lar las relaciones entre sus miembros mediante normas que posibiliten la convivencia. El término «Derecho» suele aludir a las conductas dirigidas a crear, aplicar, o cumplir esas normas; al resultado de esa actividad formalizada en un conjunto de normas o reglas sociales de comportamiento; así como a los valores para la convivencia que inspiran, o a cuyo logro se orientan, esas conductas y normas; y todo ello en un ámbito históricamente delimitado. El Derecho consiste, precisamente, en esa experiencia de vida colectiva que se puede definir como: conjunto de acciones sociales creadoras «de» o reguladas «por» normas, que deben establecer un orden justo en un determinado contexto bistórico. El Derecho posee una incuestionable significación social, normativa y axiológica, pero no puede reducirse unilateralmente ni al hecho social, ni a la norma, ni al valor. Por eso las tentativas doctrinales encaminadas a lograr las más altas cotas de claridad, rigor y sistematicidad en función de negar las dimensiones social y valorativa del Derecho para circunscribirse a su faceta sistemática y normativa, terminan siendo una pura abstracción.

Las tres dimensiones o planos del Derecho se interfieren e implican entre sí de forma necesaria. Aislarlos, como si no existiera comunicación entre ellos, en función de un criterio «estético» de perfección o armonía del sistema lógico-formal, no sólo es erróneo desde el punto de vista metodológico, sino también peligroso desde el político. Ya que la coherencia lógica y el rigor sistemático de un ordenamiento jurídico no representan por sí solos una garantía de la legitimidad o justicia de sus contenidos normativos. En cualquier experiencia jurídica se advierten esas tres dimensiones básicas del Derecho. En un proceso penal por homicidio sobrevenido como consecuencia de un accidente de tráfico, se parte de un hecho de la vida humana: la muerte de una persona a consecuencia de un atropello; supuesto que ha sido regulado (tipificado) por las normas del Código Penal; y ello en función de que la vida humana se considera un valor que el ordenamiento jurídico debe proteger.

Es cierto que la historia registra numerosos ejemplos de sistemas de Derecho positivo alejados o abiertamente contrarios a la justicia y que incluso en los ordenamientos jurídicos legítimos (Estados de Derecho) pueden darse episodios de injusticia. Pero, precisamente, se pueden calificar esas experiencias de injusticia como tales, porque existe un ejercicio de racionalidad intersubjetiva que tiende hacia el Derecho correcto. Si no existiera una experiencia racional paradigmática del Derecho justo, no podrían detectarse sus formas turbias, deficientes o degradadas. En el orden jurídico los episodios de injusticia son formas parasitarias de la perfección. Porque, los ejemplos injustos del Derecho existen gracias a que existe en los hombres la convicción racional de que es posible y deseable organizar la vida social no sólo en términos de orden y coacción, sino según reglas que salvaguarden las libertades y el bienestar colectivo, es decir, según los principios de un Derecho justo ${ }^{45}$.

La condición tridimensional del Derecho invita a conjeturar la posibilidad de que esa condición sea corroborada a través de las tres dimensiones en las que se desglosa el juzgar. Porque, resulta obvio que la significación sensitiva y perceptiva del juicio alude a hechos conformadores de experiencias jurídicas. La componente racional en la que

${ }^{45}$ Cfr. A. E. Pérez LuÑo, Lecciones de Filosofía del Derecho. Presupuestos para una filosofía de la experiencia jurídica, 9. ${ }^{a}$ ed., Sevilla, Mergablum, 2006, pp. 43 y ss.; id., Teoría del Derecho, cit. pp. 38 y ss. 
todo juicio pretende fundarse, se trata de un valor $\mathrm{y}$, por tanto, consiste en una aspiración hacia el juicio justo. Asimismo, la actividad decisoria en la que el juzgar consiste debe realizarse en el seno de sistemas y estructuras normativas, que la preserven de la arbitrariedad.

La tarea de juzgar representa un aspecto básico e insoslayable de la experiencia jurídica. Contribuir a clarificar su significado ha sido el principal propósito de estas reflexiones. Al concluirlas estimo que del itinerario reflexivo que se ha seguido hasta aquí. Pueden inferirse algunas consecuencias:

1. $\left.{ }^{a}\right)$ Que el intento de responder a la pregunta: ¿qué significa juzgar? Reenvía a otras dos cuestiones concomitantes: el problema de la creación judicial del Derecho y los ingredientes constitutivos del juicio.

2. ${ }^{a}$ Que de las distintas concepciones jurídicas sobre la dimensión creativa de la función judicial, de las que se ha esbozado un mapa de modelos teóricos, sólo dos resultan abiertamente incompatibles con el Estado de Derecho: el modelo demiúrgico y las doctrinas que postulan el arbitrio judicial.

3. ${ }^{a}$ Que el valor teórico-jurídico de los seis modelos restantes que integran esa propuesta tasonómica se halla en directa relación con su capacidad explicativa para describir la tarea de juzgar en los distintos sistemas del constitucionalismo comparado. Ello no es óbice para que la filosofía jurídica pueda proponer modelos prescriptivos de lo que estime debe ser el paradigma ideal de la función de juzgar en el Estado de Derecho.

4. ${ }^{a}$ Que para elucidar el sentido del juicio me parece más fértil la investigación de los procesos vertebradores de la decisión judicial, que la reincidencia en los consabidos debates sobre si los jueces crean o no Derecho. Esta opción metódica permite plantear el significado del juicio como resultado de un proceso en el que se articulan las percepciones sensitivas, el razonamiento y la voluntad, normativamente encauzada, del juzgador.

5. a) Que el ámbito normativo, en el que la decisión judicial se inscribe y se explicita, no agota su significado pleno. La decisión del juez es una manifestación de justicia procesal, es decir, una tarea realizada desde las normas vigentes en un ordenamiento jurídico. Pero eso no exime al juez de la búsqueda de la solución correcta del caso concreto, en términos de justicia material. Justicia formal y justicia material deben implicarse plena y simultáneamente en la tarea de juzgar. Esta propuesta se aparta de algunas de las decisiones de nuestro Tribunal Constitucional que, como se ha tenido ocasión de exponer supra sustentan que la exigencia de motivación racional de las decisiones judiciales se circunscribe a la correcta aplicación del Derecho, sin que se extienda al acierto, en términos de justicia material, del caso concreto.

Más acorde con una interpretación sistemática de nuestro vigente texto constitucional me parece la tesis contraria, la que auspicia la conexión del valor superior de la justicia, entendida en su acepción material, que dimana del art. 1.1. de la CE con su versión formal, que se concreta en las garantías procedimentales prescritas en el art. 24 de la propia CE.

Aún no siendo la opción herméutica prevalente en la jurisprudencia del TC, la tesis aquí propuesta se halla avalada por alguna de sus decisiones. Así, la que proclama que: «el principio de justicia (art. 1.1) y, por extensión, el de la fuerza vinculante de los 
derechos fundamentales (art. 53.1CE) lleva a extremar la preocupación por la justicia del caso concreto y a declarar la invalidez de todos los actos de los poderes públicos que los desconozcan, o que sean resultado de un procedimiento... en el curso del cual hayan sido ignorados» (STC 63/1982, FJ 3).

La importancia de la dimensión axiológica del juicio ha sido destacada por R. DwoRKIN en su último libro cuyo título, muy significativo a los efectos de esta exposición es Justice in Robes (La justicia con toga). En esa obra DworkIN narra el episodio en el que el célebre juez O. Wendell HolmES magistrado del Tribunal Supremo americano, invitó a un joven a acompañarle en su coche. Cuando el joven se apeó saludó al juez y a modo de reconocimiento y despedida, le dijo: «Haga justicia, magistrado». HoLmES paró el vehículo y se dirigió al joven y le dijo: «ese no es mi trabajo». DwORKIN reprocha el que cualquier juez no tenga como misión básica y radical el hacer justicia. Para DwORKIN la tarea de juzgar no consiste en la mera aplicación del Derecho positivo, sino en la búsqueda de la sentencia justa. Los jueces, en opinión de DwORKIN, no deben limitar su quehacer a la mera identificación de las normas aplicables a cada proceso. De modo especial, en aquellos casos en los que de esa aplicación se derivarían consecuencias abiertamente injustas o ineficaces, deben remitirse a los principios en los que se insertan los grandes valores morales y políticos de la comunidad, para propiciar la sentencia justa ${ }^{46}$.

Si bien se mira, estas recientes inquietudes formuladas por el célebre jurista norteamericano DwORKIN, no hacen sino reformular la vieja máxima tomista a tenor de la cual: «Iudex est interpres Iustitiae» ${ }^{47}$.

${ }^{46}$ R. Dworkin, Justice in Robes, cit., pp. 1 y 25 y ss.

47 TomÁs de Aquino, Summa Theologiae, II-II, q. 67, a.3c. 